\title{
MULTI VARI ABLE SET POINT TRACKING USING POLE ZERO PLACEMENT CONTROLLERS
}

\author{
G. M. EI-BAYOUMI ${ }^{*}$, S.D. HASSAN ${ }^{* *}$
}

\section{ABSTRACT}

The paper describes the theory and application of multi-input/multi-output (MIMO) self tuning controllers where the control objective is the tracking of reference signals. The two schemes previously introduced by the authors for SISO case are extended for the case of MIMO. The two schemes require pole placement of the closed loop transfer function as well as zero placement of the error transfer function. The problem in the case of MIMO systems transfer function. The pre difficult than that for SISO, mainly because, the
is more
matrices describe the system are not commute. Simulation example is given to demonstrate that the second scheme is more suitable than the first one.

\section{INTRODUCTION}

Several papers have been recently appeared on multivariable self tuning control. The earlier papers extended the minimum variance controller to multivariable systems. To overcome the restriction of stably invertible (minimum phase) system the technique of Clarke and Gawthrop (8) has been extended to multivariable systems. More recent papers have, however, focused on pole assignment objectives. The attractiveness of pole assignment methods include their ability to handle nonminimum phase systems, and the fact that desired closed loop performance characteristics are easily specified via pole configuration. Furthermore new classical objectives, such as decoupling and the reduction of steady state errors, introduce slight modifications of the basic algorithms.

In this paper, we shall extend the concept of set point tracking to the case of multivariable systems. This concept is modified and studied well in the case of SISO systems. The paper extend two schemes previously proposed for SISO systems (9). The two schemes are compared with the original pole placement technique and proves good tracking. Also it is found that the second scheme is more suitable and give better results than the first one.

The paper proceeds as follows. Section 2 presents the OFF line design using the schemes for tracking. In section 3 the ON line algorithm is introduced. Section 4 presents a simulation example. Main results and conclusions are found in section 5 .

* Lecturer, Dpt. of Aerospace Engineering, Cairo University, Guiza, Egypt. ** Professor, Dpt. of Aerospace Engineering, Cairo University, Guiza, Egypt. 


\section{OFF LINE DESI GN}

Consider the general form of feedback control system shown in Fig. (1), where the system is an m-input/m-output linear system described by the model

$$
A\left(z^{-1}\right) y(t)=z^{-K} B\left(z^{-1}\right) u(t)
$$

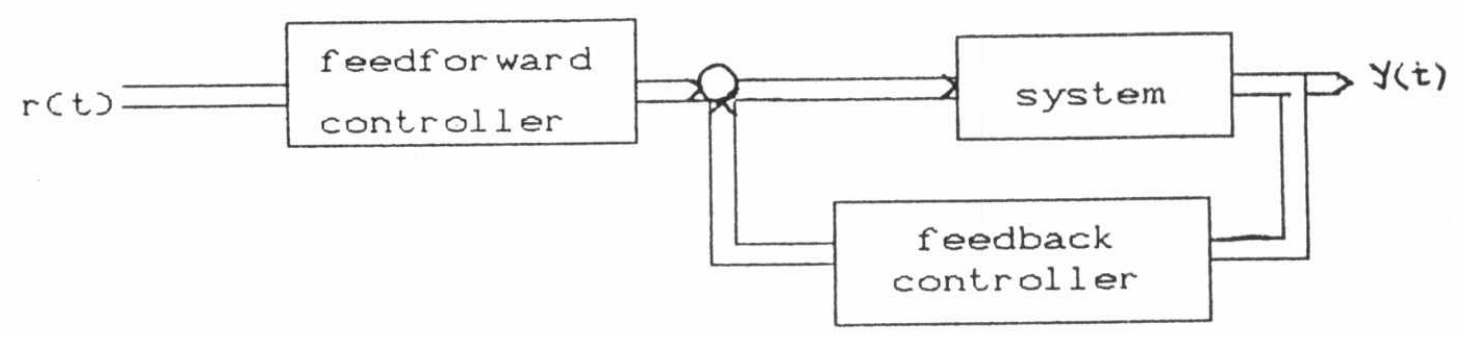

Fig.(1) General feedback control system

where $u(t)$ is $(m \times 1)$ system input vector, $y(t)$ is $(m \times 1)$ system output vector, $z^{-1}$ is the backward shift operator and $k$ is the time delay in the systom, which is -1 a multiple integer of the sampling period. $A\left(z^{-1}\right)$ and $B\left(z^{-1}\right)$ are $(\mathrm{m} \times \mathrm{m})$ matrices of order na and nb respectively and have the following structure, with $A_{0}=I$

$$
x\left(z^{-1}\right)=x_{0}+x_{1} z^{-1}+\cdots+x_{n x} z^{-n x}
$$

Let the control input vector given by

$$
u(t)=T\left(z^{-1}\right) R^{-1}\left(z^{-1}\right) r(t)+S\left(z^{-1}\right) R^{-1}\left(z^{-1}\right) y(t) \text { (3) }
$$
wherf $r(t) i s_{-1}(m \times 1)$ reference input vector and $T\left(z^{-1}\right)$,
$S\left(z^{-1}\right)$ and $R\left(z^{-1}\right)$ are $(m \times m)$ matrices of order $n t$, ns and $n r$ respectively, and have the structure given by (2), with $R_{0}=I$.

The output $y(t)$ can be written as

$$
y(t)=R\left[A R+z^{-k} B S\right]^{-1} z^{-k} B T R^{-1} r(t)
$$

and the error e(t) is given by

$$
e(t)=r(t)-y(t)
$$

$e(t)=R\left[A R+z^{-k} B S\right]^{-1}\left[A R+z^{-k} B S-z^{-k} B T\right]^{-1} \operatorname{Rr}(t)$ (4) equations ( 3 ) and (4) are the basic equations for pole placement and set point tracking.

\subsection{First Scheme :}

In the first scheme it is assumed that $T\left(z^{-1}\right)=S\left(z^{-1}\right)$ and therefore equations ( 3 ) and (4) becomes

$$
y(t)=R\left[A R+z^{-k} B S\right]^{-1} z^{-k} B S R^{-1} r(t)
$$




$$
e(t)=R\left[A R+z^{-k} B S\right]^{-1} A R r(t)
$$

in equation (G) $R$ is chosen such that the modes of the input are cancelled by $R$, so let us assume that

$$
r(t)=\left\{\frac{N_{1}\left(z^{-1}\right)}{M_{1}\left(z^{-1}\right)}, \ldots ., \ldots, \frac{N_{m}\left(z^{-1}\right)}{M_{m}\left(z^{-1}\right)}\right\}^{T}
$$

In order to cancel $M_{i}\left(z^{-1}\right), i=1, \ldots, m$, let

$$
R=R_{D} \cdot R 1
$$

where $R_{D}=\prod_{i=1}^{m} M_{i}\left(z^{-1}\right) I_{m \times m}$

The pole placement problem is to find $R$ and $S$ such that the closed loop transfer function has certain poles, which lead to the Diophantine equation

$$
A R+z^{-k} B S=A_{m} A_{0}
$$
Both $A_{m}$ and $A_{0}$ are $(m \times m)$ matrices, where $A_{m}$ is the desired characteristic polynomial of the closed 100 p system and $A_{0}$ is another polynomial which can be considered as the observer polynomial. Substitute from (9) into (10), let $A_{m}$ $A_{0}=A_{m 1}$ and $A R_{D}=A_{1}$, we get

$$
A_{1} R_{1}+z^{-k} B S=A_{m 1}
$$

Thus equation (11) can be solved for $R_{1}$ and $S$. Then $R$ is determined from equation ( 8 ).

2.2. Second Scheme :

In the second scheme, $T$ is chosen different from $S$, and thus equations ( 3 ) and (4) are used. In equation (3) $S$ and $R$ are chosen such that

$$
A R+z^{-k} B S=A_{m} A_{0}=A_{m 1}
$$

Substitute from (12) in ( 4 ), we get

$$
e(t)=R\left[A R+z^{-k} B S\right]^{-1}\left[A_{m 1}-z^{-k} B T\right] R^{-1} r(t)
$$

In equation (13) $T$ is chosen such that it cancels the modes of $r(t)$, let

$$
A_{m 1}-z^{-k} \text { B } T=R_{D} R_{2}
$$

where $R_{D}$ is given by equation (9), and $R_{2}$ is another matrix to satisfy the compatibility degree of equation (14). Rearranging equation (14)

$$
R_{D} R_{2}+z^{-k} B T=A_{m 1}
$$


Equation (15) is solved for $T$ and $R_{2}$. Note $R_{2}$ is not of interest.

\subsection{Solution of the Diophantine Equation}

The solution of the Diophantine equation of the form

$$
A R+z^{-k} B S=A_{m 1}
$$

has a unique solution, if and only if, the following conditions are satisfied [ 23$]$

$$
\begin{aligned}
& \mathrm{nr}=\mathrm{nb}+\mathrm{k}-1 \\
& \mathrm{~ns}=\mathrm{na}-1 \\
& \mathrm{nam} 1<=\mathrm{na}+\mathrm{nb}+\mathrm{k}-1
\end{aligned}
$$

The solution is obtained by equating equal powers of $z^{-1}$ in both sides of equation (16), which is transformed to a set of simultaneous equations.

It is seen that solution of Diophantine equation requires inversion of matrix of order $(n a+n b+k-1) * m$, subtraction, and matrix multiplication.

\section{4. Control Law Application}

The control law of equation (3) can be implemented by introducing a further assumption of commutivity, it is assumed that, there exist $\bar{S}$ and $\bar{R}$ such that

$$
S R^{-1}=\bar{R}^{-1} \bar{S}
$$

where $\bar{S}$ and $\bar{R}$ are $(m \times m)$ matrices of order $n s$ and $n r$ respectively. The solution of equation (18) leads to a system of 1 inear equations.

The solution of equation (18) requires inverse of matrix of order $m *(n r+n s)$, unless $n r=0, i . e$. $n b+k=1$, where $\bar{R}=I$ and $\bar{S}$ $=\mathrm{S}$. Or when $\mathrm{m}=1$, where the transformation is unnecessary. From equation (18) the control law is given by

$$
u(t)=\bar{R}_{t}^{-1} \bar{T} r(t)-\bar{R}_{s}^{-1} \bar{S} y(t)
$$

\section{ON LINE DESIGN}

When the parameters of the system are unknown, then, they must be estimated using recursive least square, and the controller is redesigned in each step using the estimated paameters instead of the true ones.

\section{SIMULATION EXAMPLE}

The schemes proposed for tracking as well as pole placement technique are compared using a simulation example. Consider the 2 -input/2-output system described by equation (1), where 


$$
\begin{aligned}
& A\left(z^{-1}\right)=I+A_{1} z^{-1}+A_{2} z^{-2} \\
& B\left(z^{-1}\right)=B_{0}+B_{1} z^{-1}, K=1
\end{aligned}
$$

given

$$
\begin{aligned}
& A_{1}=\left[\begin{array}{cc}
-1.4 & -0.2 \\
-0.1 & -0.9
\end{array}\right] \\
& B_{0}=\left[\begin{array}{cc}
1 & 0 \\
0 & 0
\end{array}\right]
\end{aligned}
$$$$
A_{2}=\left[\begin{array}{cc}
0.48 & 0.1 \\
0 & 0.2
\end{array}\right]
$$$$
B_{1}=\left[\begin{array}{cc}
1.5 & 1 \\
0 & 1
\end{array}\right]
$$

The model 15 chosen to be ${ }_{1}+A_{m 2} z^{-2}$
\[ A_{m}(z)=I+A_{m 1} z^{-1}+A_{m} \]

given $\quad A_{m 1}=\left[\begin{array}{cc}-1.0 & 0 \\ -0.1 & -0.7\end{array}\right] \quad A_{m 2}=\left[\begin{array}{cc}0.25 & 0 \\ -0.050 .12\end{array}\right]$

while the observer polynomial is taken as $A_{0}\left(z^{-1}\right)=I$. The case ${ }_{1}$ of periodic step input is considered, where $M\left(z^{-1}\right.$ ) Simulation for the 3 cases are shown in figures $2,3,4$ for the off line design and figures $5,6,7$ for the On line design. It is very clear that both schemes give good tracking than design using pole placement only. It is also clear by comparing figures 3 and 4 as well as 6 and 7 that the second scheme give better tracking specially at sudden changes of reference signal.

\section{CONCLUSIONS}

Two schemes for better set point tracking which are previously adopted for SISO systems are generalized here for the case of MIMO. The two schemes still prove good tracking. The second scheme is advantageous than the first one, both in the results obtained as well as computations required for the controller design.

\section{REFERENCES}

1. Allidina, A.Y., and Hughes, F.M., 'Generalized self-tuning controller with pole assignment', IEE Proc.,1980, Vol. 127,Pt. D, No.1,pp. 13-18

2. Astrom, K.J., and Wittenmark, B.,' Computer controlled Systems', Prentice Hall, 1984

3. Astrom, K.J., and Wittenmark, B.,'Self-tuning controllers based on pole zero placement', IEE Proc. D. Control Theory and Appl.,1980,127, (3), pp. 120-130

4. Astrom,K.J., and Eykhoff, P., 'System Identification', Automatica, 1977, Vol. 7,pp. 123-162.

5. Astrom, K.J., Borison, U., Ljung, L., and Wittenmark, B., 'Theory and applications of self tuning regulators', Automatica, 1977, Vol . 13,pp. 457-476 
6. Chin, M. L., and Bor-Sen, C., 'Adaptive controller with desired pole/zero assignment, IEE Proc.D. Control Theory and Appl., 1986,133, (6), ,pp. 301-306

7. Clark, D.W., and Gawthrop P.J.,'Self-tuning control', Proc. IEE, 1979, Vol. 126, No. 6, pp. 633-640

8. Clark, D.W., and Gawthrop P.J., 'Self-tuning controller', Proc. IEE, 1975, vol. 122, No. 9, pp. 929-934

9. El-Bayoumi, G.M., Hassan, S.D., and Bayoumi, M.S., 'Modified Pole-Zero Placement for Better Set-Point Tracking', Scientific Engineering Bulletin, Cairo University, Faculty of Engineering, 1990.

10. Eykhoff, P.,'System identification', John wiley \& Sons, 1974

11. Franklin, G.F., and Powell, J.D.,'Digital control of dynamic systems', Adison Wesley, 1980

12. Fuches, J.J.J.,' Explicit self-tuning methods', IEE Proc., 1980, Vol. 127,Pt. D. , No. 6,pp. 259-264

13. Gawthrop, P.J.,'Some interpretations of the self-tuning controller', Proc. IEE, 1977, Vol. 124, No. 10,pp. 889-894

14. Harris, C.J., and Billings, S.A.' Self-tuning and adaptive control, The Institution of Electrical Engi neerings, 1981

15. Kinnaert, R., Hanus, R. and Henrotte, J. L., 'A new Decoupling Precompensator for Indirect Adaptive Control of Multivariable 'Systems', IEEE Trans. Automat. Cont. 1987, Vol. AC-32, No. 5, pp 455-459.

16. Tade, M. O., and Bayoumi, M. M., 'Adaptive Decoupling of a Class of Multivariable Dynamic Systems using Output Feedback', IEE Proc., 1986, Vol. 133, Pt. D, No. 6,pp 265-275

17. Wellstead, P.E., Prager, D., and Zanker, P., 'Pole assignment self-tuning regulator', Proc. IEE, 1979, Vol. 126, No. 8, pp. $781-787$

18. Penttinen, J., and Koivo, H.N., Multivariable Tuning Regulators for Unknown Systems', Automatica,1980, Vol. 16, pp 393-398.

19. Phillips, C.L., and Nagle, H. T.,'Digital control systems', Prentice Hall,1984

20. Prager, D. L., and Wellstead, P.E.,' Multivariable Pole Assignment Self Tuning Regulators', IEE Proc., 1980, Vol. $128, \mathrm{Pt} . \mathrm{D}$, No. 1 , pp $9-18$

21. Puthenpura, S.C., and MacGregor, J.F., 'Pole-zero placement controllers and self-tuning regulators with better set-point tracking', IEE Proc. D. Control Theory and Appl.,1987,134,(1), pp. 26-30 

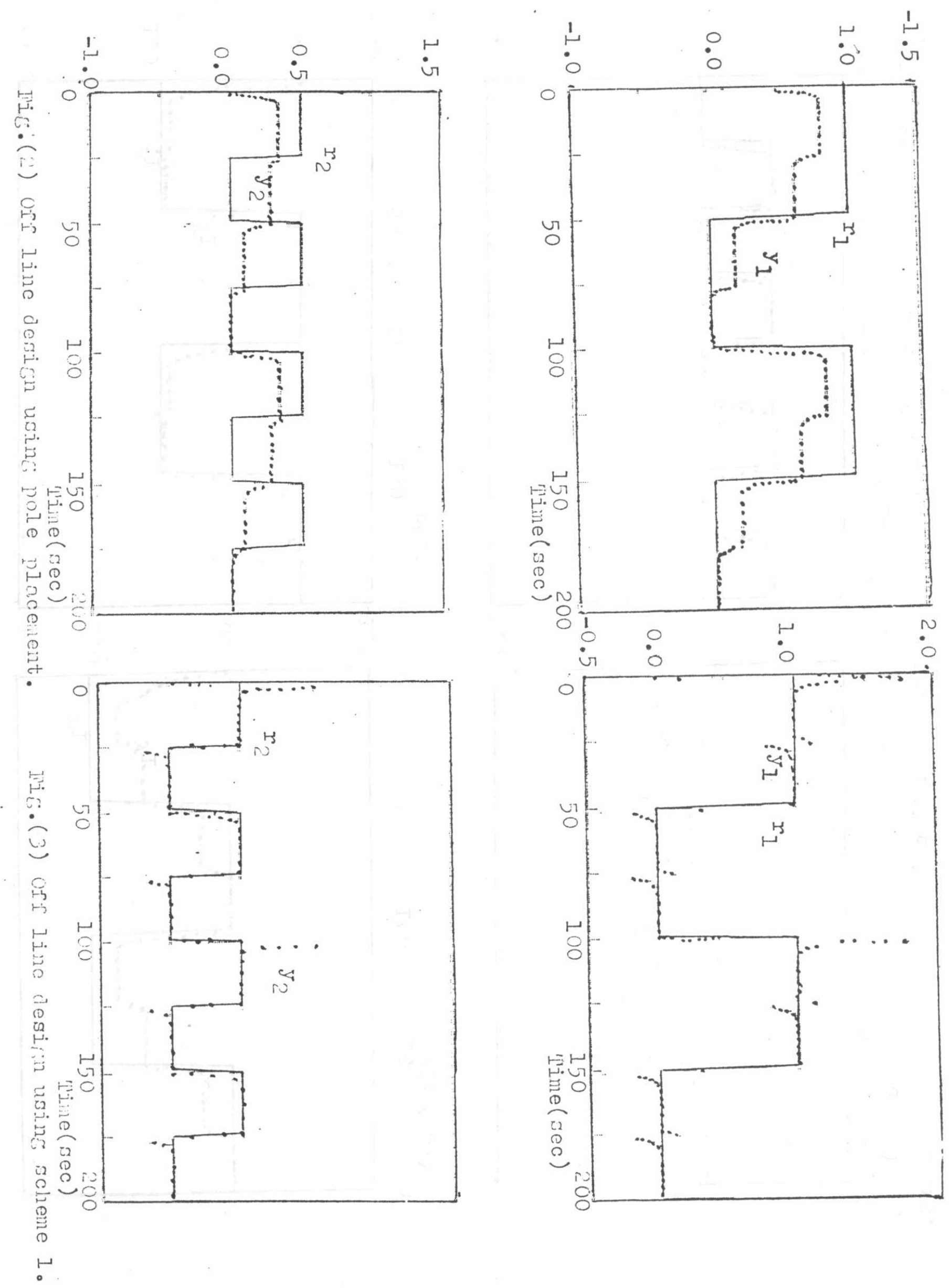
FIFTH ASAT CONFERENCE

4 - 6 MAY 1993, CAIRO
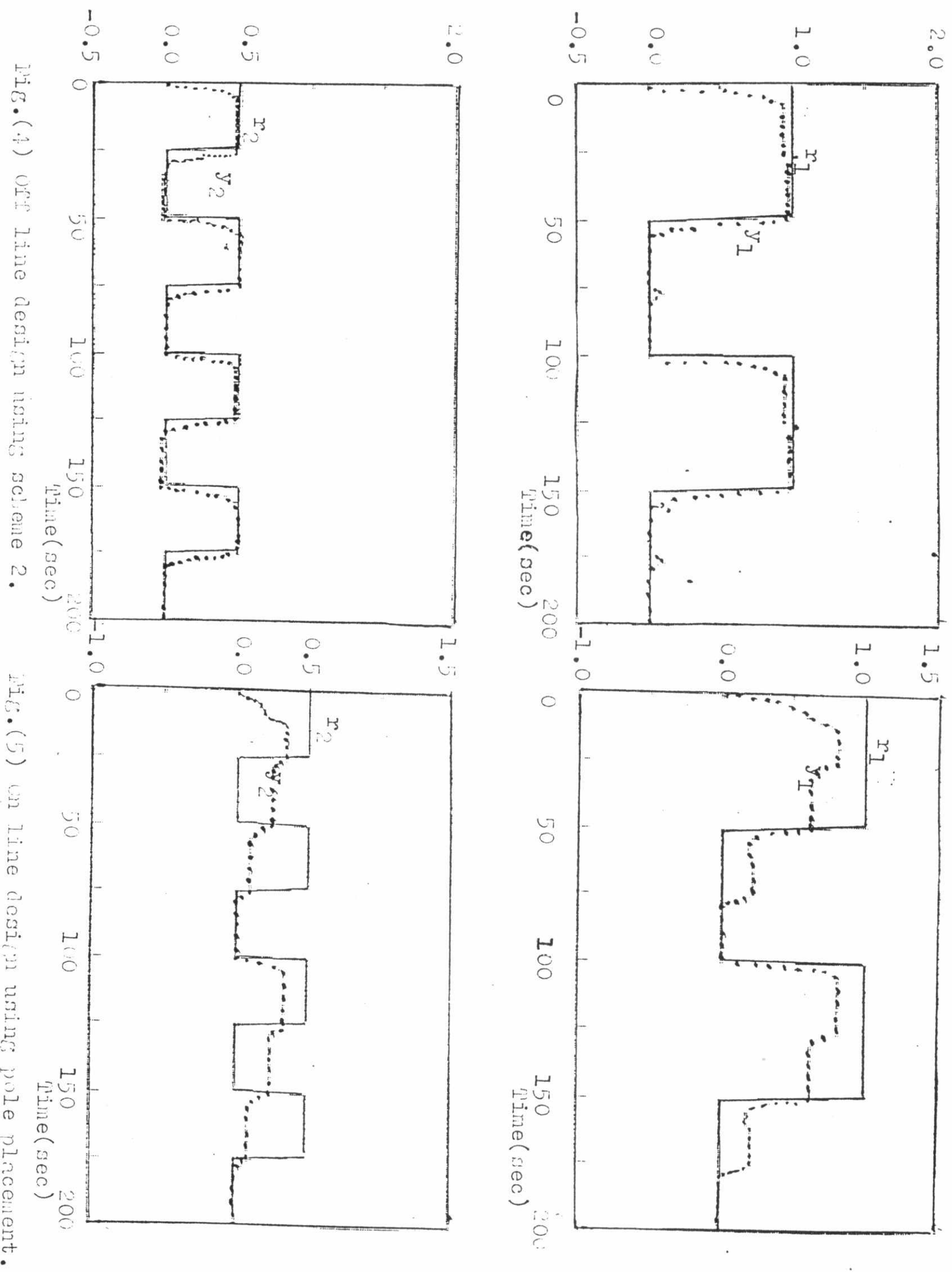
\begin{tabular}{|l|l|}
\hline GC -4 & 333 \\
\hline
\end{tabular}

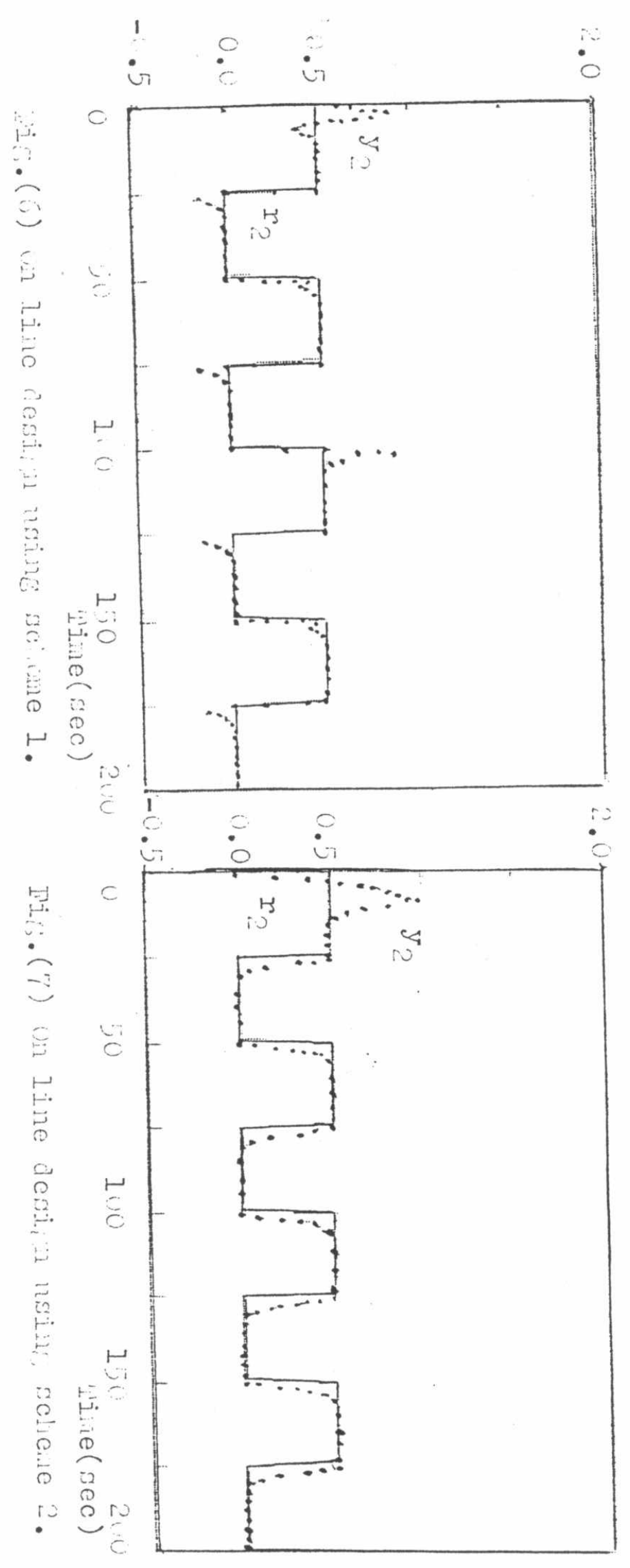

FIFTH ASAT CONFERENCE

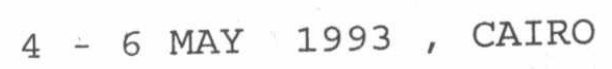

$\stackrel{1}{\circ} \div \quad \div$

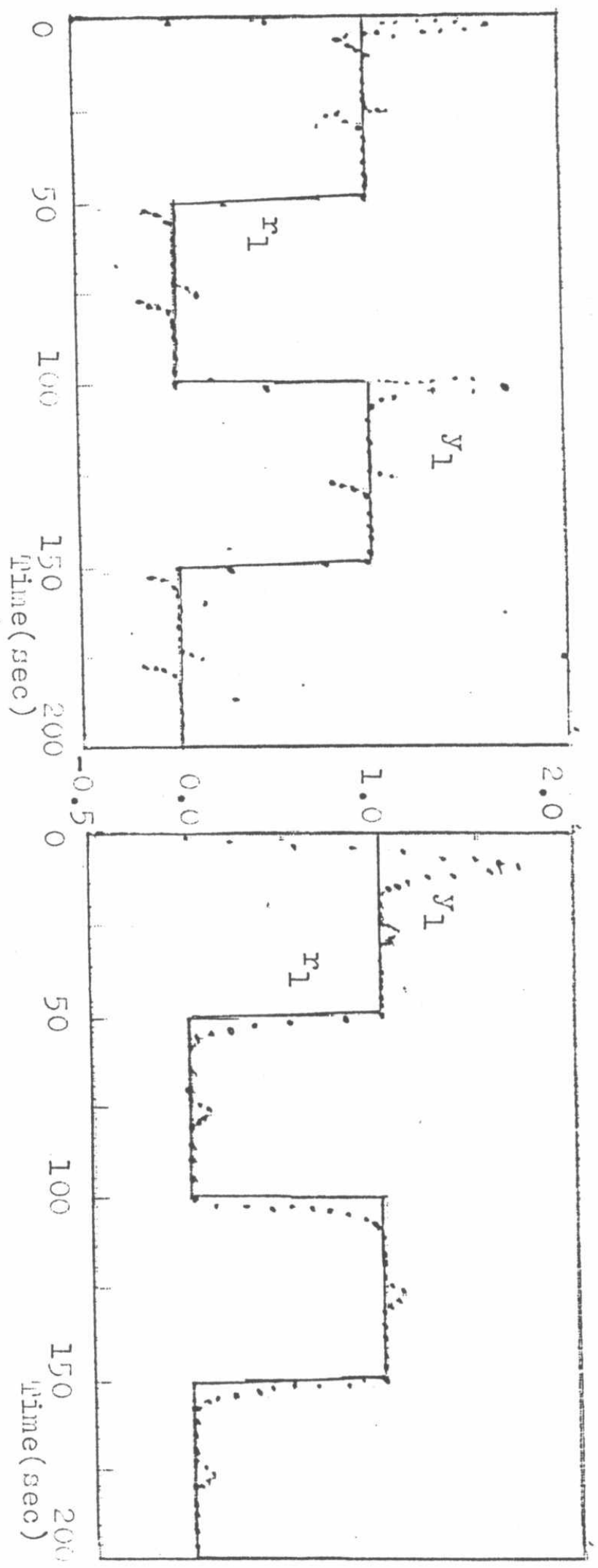


A MODEL REFERENCE ADAPTIVE CONTROLLER (MRAC) WITH PERIODIC RESETTING OF ADAPTATION MECHANISM (PRAM)

\author{
ADEL T. Y. TAWFIK *, A.M. WAHDAN **
}

\title{
ABSTRACT
}

It has been assured that standard adaptive control algorithms, designed in the so-called ideal case, would likely become unstable when one takes disturbances and neglected dynamics into account.

For the stability problems to be tackled; we propose a modified model reference adaptive controller that introduces the concept of periodic resetting of adaptation mechanism. In order to attain the best feasible performance; an optimum adaptation-time is computed on-line, via minimization of certain quadratic criterion.

In this paper, a modified algorithm of MRAC with (PRAM) has been developed. Such a controller can provide stability with better performance to a large family of real plants, where sinusoidal disturbances and unmodeled dynamics are most probable.

The proposed scheme prevents the dangerous problems due to unbounded parameter drift present in avallable MRAC schemes, in such practical conditions. The analytical arguments and improvements provided by the proposed algorithm, has been verified by simulation results.

* Brig.Gen.Eng. Adel T.Y. Tawfik, E.A.F., Ph.D. candidate, Dpt.of Computers and Systems Eng., Ain-Shams Univ., Cairo, Egypt.

** Prof.Dr.A.M. Wahdan, Dpt. of Computers and Systems Engineering, Ain-Shams University, Cairo, Egypt. 


\section{INTRODUCTION}

An intensive investigation study of the stability and robustness properties of a wide class of conventional adaptive control algorithms in the presence of unmodeled high-frequency dynamics and persistent output disturbances, has been carried out(Rohrs and others, [1.1]). Their main conclusion was that:

1) Sinusoidal reference inputs at specific frequencies and / or,

2) Simmolal output disturbances at any frequency (including dc), can cause the loop gain to increase without bound leading to instability.

Since then, ROBUST MODEL REFERENCE ADAPTIVE CONTROL(MRAC) for real systems, under practical conditions, have been extensively studied in the literature during the last decade. For linear single-inputsingle-output (SISO) systems, several robust modifications have been proposed that can be turned into the following main classes:

(i) Modifyiug the adattive law, such as, dead zone : ([10],[15]), " modificotion:[2], modification:[8], dead zone using an upper bount of the plant parameters [5], and with a variable width: $([?],[[])$, control] gin limilex: :1.7.

(ii) Thoraing thr richness of the reference input: (Narendra and Annaswamy [7]) derived the sufficient conditions on the persistent excitation of the roforcnce input, given the maximum amplitude of disturbance, for the signals in the adaptive system to be globally bounded.

Concerning nonlinear systems, several researches dealing with robust adaptive control are now available in the literature, however, fow results have beon obtained(see e.g.[11],[16],[3], [4], and [13]):

In this i ger, we propose the PRAM modification as a solution for stability problems of a plant subject to disturbances and unmodeled dyramics.

The proposed modjfication makes a conventional adaptive controller globally stable, am robust to uncertainties; in the sense that wl the signuls in the loop remain bounded. For reviewing the gcneral. structure of a standard MRAC algorithm and the associated infinite gain operators in the presence of such uncertainties (unmodeled dynamics and disturbances); the reader may refer to [13], [14], anc] [17].

\section{PRAM - MODJFICATION}

The essential idea of PRAM is to reset the adaptive gains to their optimum nominal values periodically. The time-period after which the adaptation mechanism is reset periodically, is named the adrutation period ( $T \cdot$ ). By defining a permissible limit for the 
ratio of adaptive gain drift to system mismatch error ( $\|\tilde{\mathrm{K}}(\mathrm{t})\| /$ $\|\in(t)\|$ ), that would not be exeeded, we can derive the upper bound for the adaptation-period ( $\mathrm{T}_{\mathrm{a}}$ ) '. Also a lower bound ( $\mathrm{T}_{\mathrm{a}}$ ) can be determined according to the transient reponse of the control system. Depending on the selected value of the adaptation period, the resetting mechanism can be designed. Thus, the proposed modified algorithm is capable to prevent the undefinite drift of controller parameters $\tilde{\tilde{k}}$ (t); by assuming a finite time of adaptation-period, after which the drift of parameters will be reset to zero periodically. The limiting bounds of adaptation period ( $\mathrm{T}_{\mathrm{min}}$, ' $\mathrm{T}_{\max }$ ), ${ }$ will be properly evaluated in order to contain the drift of adaptive parameters $\tilde{k}(t)$ within the assumed permissible limits. PRAMmodification can be introduced in the adaptive mechanism of the available standard MRAC algorithm, as shown with CA1 in Fig.1.

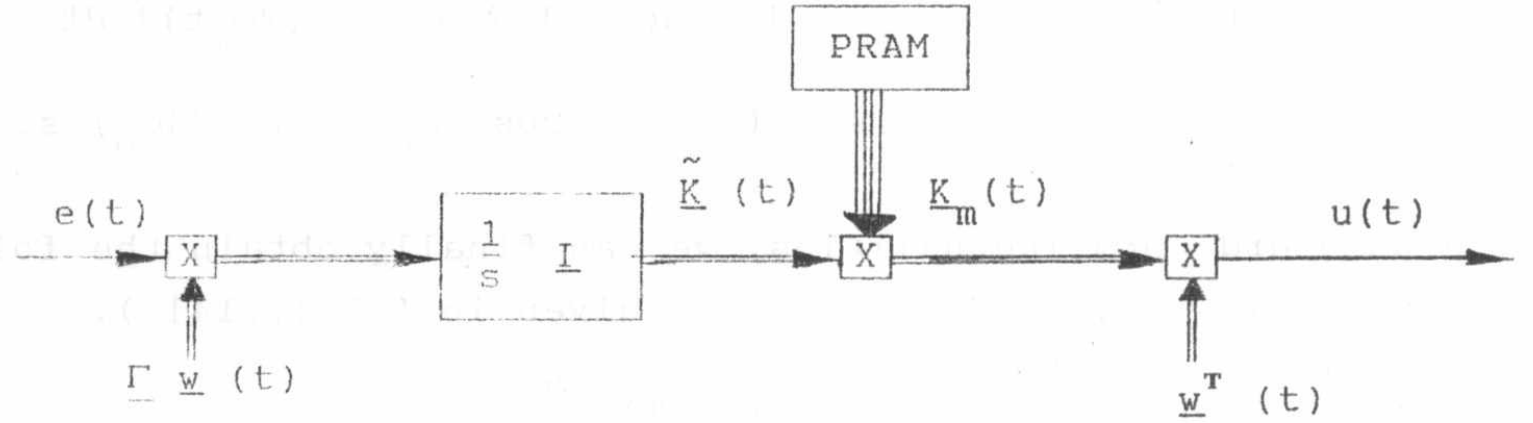

Fig.1. CA1. Modified Adaptive Parameters $\tilde{\mathrm{k}}_{\mathrm{m}}(t)$ using RRAM.

\section{ADAPTATION - PERIOD ( $\left.\mathrm{T}_{\mathrm{a}}\right)$}

Using one of the available standard adaptive algorithms (CAI is chosen for its simplicity), and considering an additive output disturbance of the form

$a(t)=d_{0} \sin \left(\omega_{0} t\right)$

Then, the plant output will be

$y(t)=y(t)+c(t)$

The mismatch error between the plant output and the desired model output, e (t), even at full adaptation convergence state, will have a residul sinusoidal component of the form

$e(t)=a \sin \left(\omega_{0} t+\Phi\right) \cong d_{0} \sin \left(\omega_{0} t+\Phi\right)$

For simplification of the mathematical derivation, a zero value 
for the phase-shift angle (क) is considered, and a scalar auxiliary signal $w(t)$ is assumed as

$w(t)=b+c \sin \left(\omega_{0} t\right)$

where $a, b, c, d_{0}, \omega_{b}$ are assumed to be positive constants.

From equations (3) and (4) we get

$w(t) \cdot e(t)=a \sin \omega_{0} t \cdot(b+c \sin \omega t)$

$$
=a b \sin \left(\omega_{0} t\right)+1 / 2 a c-1 / 2 \operatorname{ac} \cos \left(2 \omega_{0} t\right)
$$

According to ardaptation law of cnl algorithm, as given in [14] the variation of a single controllex parameter $[\hat{k}(t)]$ will be

$\tilde{k}(t)=\tilde{k}_{0}+\int_{0}^{t} w(\tau)$ e $(\tau) d \tau$

$$
\begin{aligned}
& =\ddot{k}_{0}+\int_{n}^{t}\left[a b \sin \omega_{0} t+1 / 2 a c-1 / 2 a c \cos \left(2 \omega_{0} t\right)\right] d t \\
& =\tilde{k}_{0}+1 / 2 a c t+a b / \omega_{0}\left(a b / \omega_{0}\right) \cos \omega_{0} t-\left(a c / 4 \omega_{0}\right) \sin 2 \omega_{0} t
\end{aligned}
$$

Using standard norm inequalities, we can finally obtain the following inequality ( full derivation is given in [ 13], [14]).

$\|\tilde{\mathrm{k}}(\mathrm{t})\|_{0}^{\mathrm{T}} \geq\left(\mathrm{k}_{2}, \mathrm{~T}^{3}, 1 / 2 \quad\left(\mathrm{k}_{1} \mathrm{~T}\right)^{1 / 2}\right.$

Similarly, the uguare of error norm is

$$
\left(\|0(t)\|_{0}^{T}\right)^{2}=a^{2} \int_{0}^{x} \operatorname{Ln}^{2} \omega_{0} t a t \leq a^{2} T
$$

According to equation (3), the parameter a can be approximated by a, at some cases near final convergence state. Using (8) and (9), a ratio between drift of parameters and the error (ratio between the norms) can be obtained as

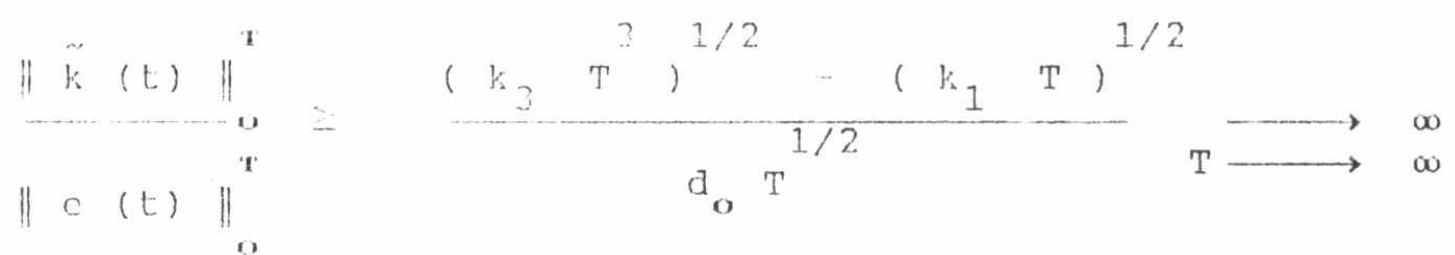

where $k_{1}=\left(\tilde{k}_{0}\right)^{2}+2\left(\frac{a b}{\omega_{0}}\right]^{2}+\left[\frac{a c}{4 \omega_{0}}\right]^{2}$, 


$$
k_{3}=\left(\frac{a^{2} c^{2}}{12}\right)
$$

Inspecting inequality (10), it is clear that as time increases, the ratio $(\| \tilde{k} t)\|/\|$ e (t) $\|)$ will icrease without bound. In this paper, we propose limiting values for adaptation time ( $\mathrm{T}_{\mathrm{amax}}, \mathrm{T}_{\mathrm{min}}$ ); in order to make the drift of parameters bounded within accepted limits.

3.1 Higher Limit ( $\mathrm{T}_{\mathrm{a}_{\max }}$ ) :

In order to make the ratio $[\|\tilde{k}(t)\| / \|$ e $(t) \|)$ not higher than a finite positive constant (L); higher limit for the adaptation - period ( $\mathrm{T}_{\max }$ ) can be evaluated,

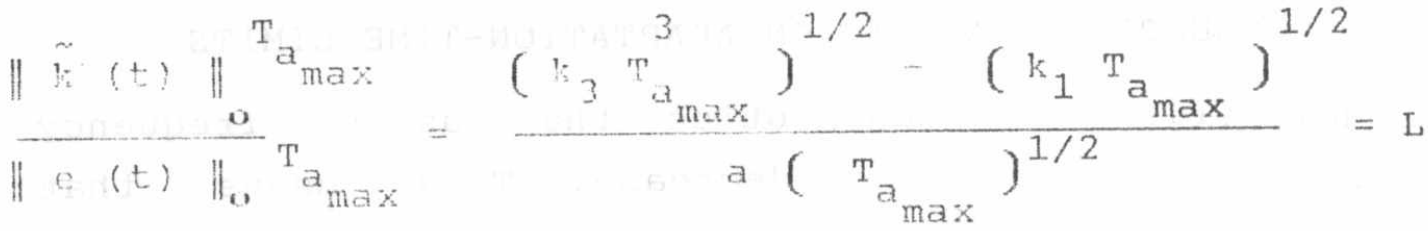

then, ${ }^{T}{ }_{\max }=\frac{\left(k_{1}\right)^{1 / 2}+a L}{\left(k_{3}\right)^{1 / 2}}$

substituting for $k_{1}$ and $k_{2}$, we can get

$$
(12)^{1 / 2}\left(a L+\left[\left(\tilde{k}_{0}\right)^{2}+2\left(\frac{a b}{\omega_{0}}\right)^{2}+\left(\frac{a c}{4 \omega_{0}}\right)^{2}\right]^{1 / 2}\right)
$$

Ta $\max$

ac

3.2 Lower Limit ( $\mathrm{T}_{\mathrm{min}}$ )

$\Lambda$ zero value for the lower limit of adaptation time, must be avoided because this prevents any sort of adaptive control to go on. The reasonable lower limit for adaptation-time can be considered as the minimum time after which a nearly zero drift of gain parameters is attained, i.e., when $\|\tilde{k}(t)\| \cong 0$.

Referring to inequality (10), we may have, 
$\left[k_{3} \mathrm{~T}_{\min }^{3}\right]^{1 / 2} \quad\left[k_{1} \mathrm{~T}_{\mathrm{min}}\right]^{1 / 2}=0$

then,

$$
\mathrm{T}_{\mathrm{a}_{\text {In } n}}=\left(\frac{\mathrm{k}_{1}}{\mathrm{k}_{3}}\right)^{1 / 2}
$$

Substituting for $k_{1}$ and $k_{3}$, we get

$$
\left[12\left[\tilde{v}_{0}\right]^{2}+24\left[\frac{a b}{\omega_{0}}\right]^{2}+\frac{3}{4}\left[\frac{a c}{\omega_{0}}\right]^{2}\right]^{1 / 2}
$$

${ }^{\mathrm{T}} \mathrm{amin}$

$a c$

\section{COMMENTARY ANALYSTS ON ADAPTATION-TIME LIMITS}

(i) From eqn. (14), one can notice that as frequency ( $\omega_{\text {, }}$ increases, ( $\mathrm{T}_{\mathrm{a}}$ ) would decrease. This means that instability of a standara MRAC system would occur sooner for highor frequency of aisturbance.

(ii) Investigating inequality (10) and eqns.(11a,b), we note that as sinusoidal disturbance amplitude do decreases; the ratio (\| $\tilde{k}(t)\|/\| u(L) \|)$ will increase. To make it more clear, consicer a very low extent of disturbance $\left(\mathrm{a}_{0}=1 \times 10^{-6}\right)$; then (10) can be approximated by (neglecting higher orders of do)

$$
\|\tilde{k}(t)\|_{u}^{T},\|t(t)\|_{0}^{2} \cong \frac{k_{0} T^{1 / 2}}{d_{0} T^{1 / 2}} \cong \frac{\tilde{k}_{0}}{d_{0}}
$$

Thus, decreasing ( $a_{0}$ ) the ratio of parameter drift to error signal is increased; thereby pushing the adaptive system faster to instability. This andysis gives a clear mathematical interpetation for the simulation results first obtained by(Rohrs, 1382 [12:), and which were amazing at that time.

(iis) ono malo aloo wote that the developed higher limit for adaptation time ( ${ }^{2} \max _{\text {, }}$, can be viewed, in some sense, as a stability indicator Eor the adaptive system subjected to mentioned practioal coneltions. 
(iv) Investigating the mathematical condition for computing ( $\left.T_{a \min }\right)$, namely $\|\tilde{k}(t)\|=0$, this state is satisfied when $k$ ( $t$ ) is nearly constant, i.c., when the variation (drift) of adaptive parameters is nearly zero. From practical experience, supported by simulalion results, we know that the drift of parameters will not approach zero until, at least, the transients of the controlled system are damped out. The transient is assumed to be over when the response error has become below certain minimum level.

Note: settling time for a second order system, when response error is reduced below $2 \%$ of its nominal value, is approximately equal to four time constants of the envelope of the damped sinusoidal oscillations.

Thus, the lower limit ( 'T' ${ }_{\text {min }}$ ) may be well approximated by

$$
\mathrm{T}_{\mathrm{min}} \cong 4 \mathrm{~T}_{\mathrm{m}}
$$

Where $\left(T_{m}\right)$ is assumed to be equal to the time constant of the desired reference model specified in the used MRAC algorithm. One may consider that the lower limit obtained by eqn.(19) is more practical than the former one given by eqn. (17).

$$
\text { 5. OPTIMAL ADAPTATION - PERIOD ( } \left.\mathrm{T}_{\mathrm{a}}\right)^{\prime}
$$

The derived equations (14) and (17) prove that, in principle, there is a feasible proper range of adaptation time, within which all signals in the adaptive system can be kept bounded in practical applications subjected to unmodeled dynamics, and inusoidal disturbances.

As most. items of eqns. (14) and (17) such as, (a,b,c, $\omega_{\mathbf{o}^{\prime}}$ and $d_{0}$ ) can not be known a priori. Besides, such items are not positive constants as what has becn assumed in section.4, but they are rather variables affecting one another. Therefore, we need to develop here an approach to determine an optimal value for the parameter $\mathrm{T}_{\mathrm{a}}$ ( in some sense) by minimizing an assumed performance criterion, on - line.

Suppose that the system is described in discrete-time form by

$$
y(t)=\frac{g_{p} q^{-d p} B^{(m)}}{\Lambda(n)}[u(t)]+v(t)
$$

Where $y$ (1.) and $u(t)$ are the output and input, respectively at time $t$ and $v(t)$ is a disturbance term, and

$$
\begin{aligned}
& B^{(m)}=1+b_{1} q^{1} \cdot b_{2} q^{-2}+\cdots+b_{m} q^{-m} \\
& A^{(n)}=1+a_{1} q^{-1}+a_{2} q^{-2}+\cdots+a_{n} q^{-n}
\end{aligned}
$$


Where $\mathrm{q}^{-1} \mathrm{is}$ the backward shift operator, $g_{\mathrm{p}}$ and $\mathrm{dp}$ are the gain and delay of the system respectively. Assuming the system (20) is controlled by a conventional adaptive controller with PRAM modifination, then the adaptive gain, the input, and the output of the system will of conrse depend on the modification parameter ' ${ }_{a}$ ' and will be denoted by $k\left(t, T_{a}\right), u\left(t, T_{a}\right)$ and $y\left(t, T_{a}\right)$.

The parameter $\mathrm{T}_{\text {a }} \mathrm{j}$ to be chosen so that a criterion of the form

$$
V\left(T_{a}\right)=E g\left(y\left(t, T_{a}\right), u\left(t, T_{a}\right)\right.
$$

ic minima. The details of a amilar approach can be found in [3], hor opoctalion i done over the stochastic signals in the systom, such us \{ $u$ (L) which was assumed in [3] to be itation w wochastic process, with zero mean and arbitrary correlation properties. Minimizing (23) could be replaced by the solution of

$$
\begin{aligned}
& 0-V\left(T_{a}\right)=E\left[g_{y}\left(y\left(t, T_{a}\right)\right) y^{\prime}\left(t, T_{a}\right)\right. \\
& \left.j_{11}\left(\because\left(1, \mathrm{~T}_{a}\right), u\left(t, \mathrm{~T}_{\mathrm{a}}\right)\right) \mathrm{u}^{\prime}\left(t, \mathrm{~T}_{\mathrm{a}}\right)\right]
\end{aligned}
$$

Here $y\left(t, \mathrm{~T}_{a}\right)$ and $"\left(t, \mathrm{~T}_{a}\right)$ denote the output and input aifferentiated with respert to $\mathrm{T}_{a}$, and $\mathrm{g}_{y}(y, u)$ is the derivative of 'j with respect to its first argument $y$, and so forth. The idea of this approach is to update Th in a negative gradient direction of the critorioit [4]. The parameter $T_{\text {a }}$ is adjusted on-line in what Le believert to be decteni direction of a quadratic criterion $v$. The parameter $T_{\text {a }}$ will converge to, at least, a local minimum of

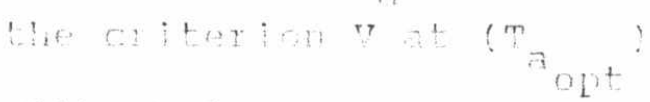

Withon! ioss of gencrality, a guadratic criterion can be assumed as

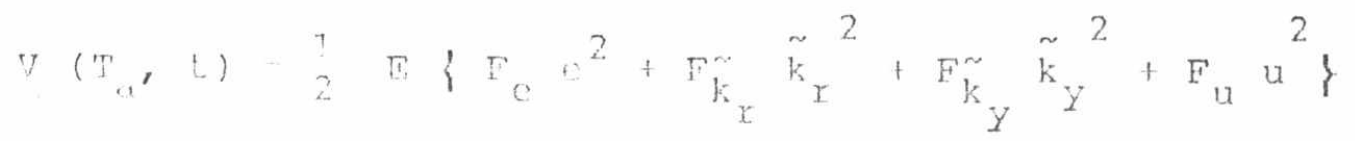

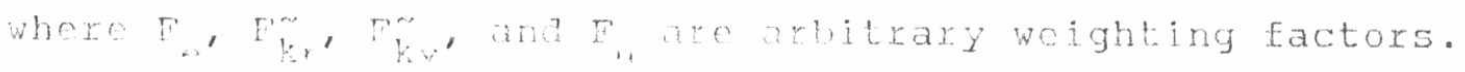

For the duaratic critorjon (25) to be minimized, we seek the solutian of the next oun.

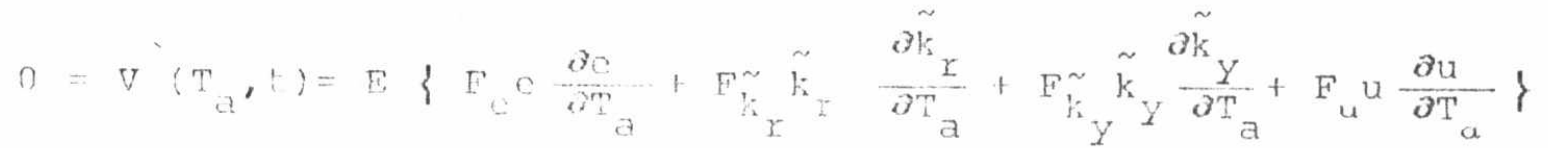


During searching process, the adaptation-time parameter ( $\left.\mathrm{T}_{\mathrm{a}}\right)$ is considered the real time $t$ which is always updated by the sampling-period ( $\left.{ }_{S}\right)$ of the discrete-time system; till the optimal value $\mathrm{T}_{\mathrm{a}}$ is reached. Hence, $\mathrm{V}$ ' can be approximated as,

$$
\begin{aligned}
v^{\prime}(t) & =E\left\{F_{e} e(t) \frac{e(t)-e(t-1)}{T_{S}}+F_{k_{r}} \tilde{k}_{r}(t) \frac{\tilde{k}_{r}(t)-\tilde{k}_{r}(t-1)}{T_{S}}\right. \\
& \left.+F_{k_{Y}}^{\tilde{k}_{Y}}(t) \frac{\tilde{k}_{y}(t)-\tilde{k}_{Y}(t-1)}{T_{S}}+F_{u} u(t) \frac{u(t)-u(t-1)}{T_{S}}\right\}
\end{aligned}
$$

Since the signals of the system are assumed to be deterministic, and the disturbance is a sinusoid with distinct frequency; then the expectation is replaced by the current values of signals and parameters.

Being interested in the instant when the gradient changes its direction, rather than getting the precise value of that gradient, $v^{\prime}$ can be rescaled as

$$
\begin{aligned}
v^{\prime}(t) & =F_{e} e(t)[e(t)-e(t-1)]+F_{\tilde{k}} \tilde{k}_{Y}(t)\left[\tilde{k}_{Y}(t)-\tilde{k}_{Y}(t-1)\right] \\
& +F_{k} \tilde{k}_{Y}(t)\left[\tilde{k}_{y}(t)-\tilde{k}_{Y}(t-1)\right]+F_{u} u(t)\left[F_{u} u(t)-u(t-1)\right]
\end{aligned}
$$

In this approach the time $\mathrm{T}_{\mathrm{a}}$ copt corresponds to the gradiant first conversion of direction from negative to positive one, just after the assumed transient-time is over(see Fig.2.). This on-line computed value ( $\mathrm{T}_{\mathrm{a}}$ ) is the local optimum cholce of adaptation-time that would ensure local minimization of performance criterion in the feasible operating conditions.

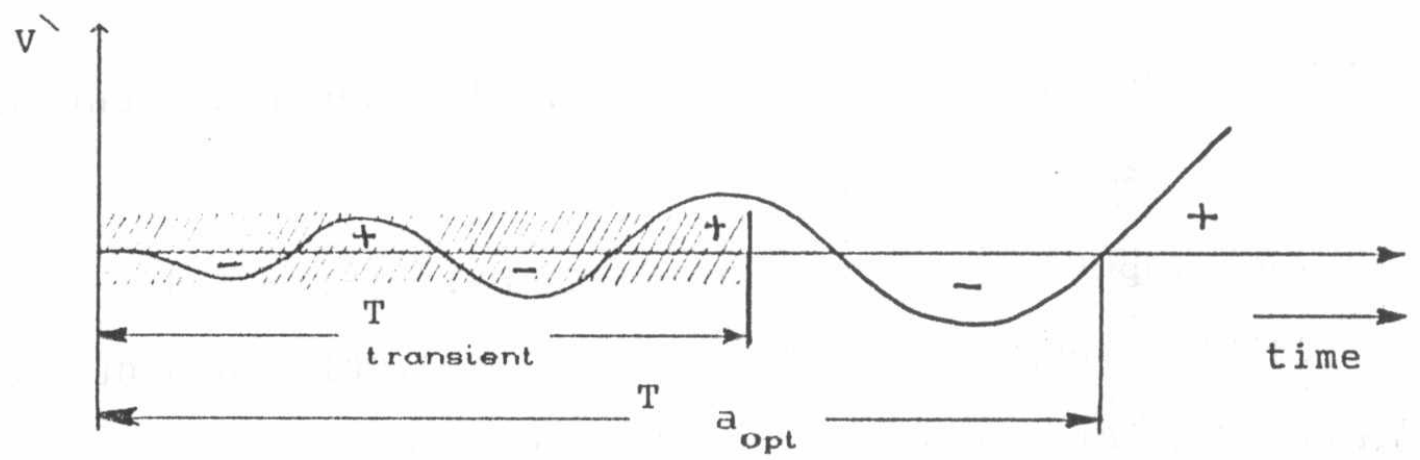

Fig. $2 \mathrm{~T}_{\mathrm{a}_{\text {opt }}}$ corresponds to first conversion of $\mathrm{V}$ 'direction. (from negative to positive after transient is over) 


\section{SIMUIATION RESUI,TS}

To illustrate the effectiveness of the proposed PRAM-modification presented in the previnus sections; consider the following example with a plant described by,

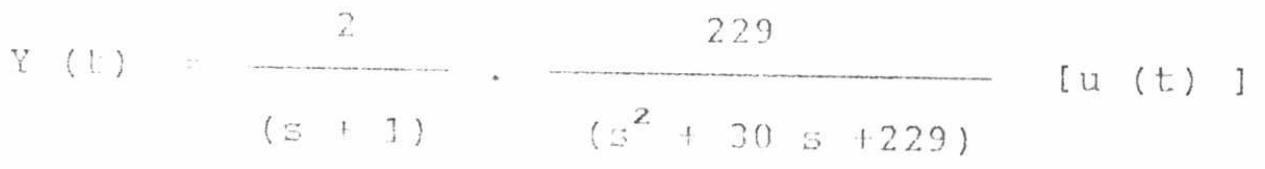
The adaptive scheme CAI [14] is used, with a first order reference
moder given as

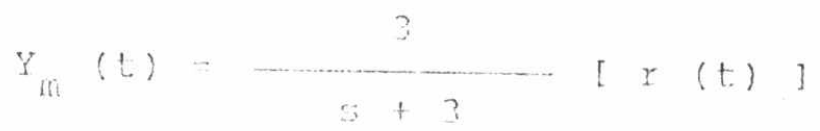

The simnations were all initialized with

$k_{Y}(0)=0.65 ; k_{Y}(0)=1.14$ which yield a nominal controlled plant with the following transfer
function

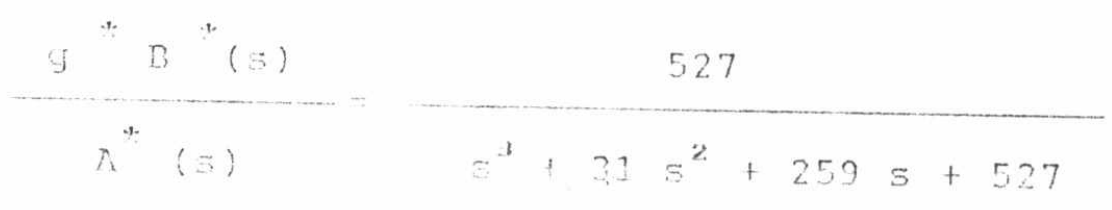

$i^{*} B^{*}$

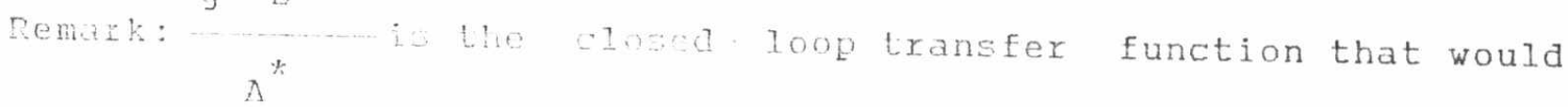

tesult if $\tilde{i}$ were identically aero,i.e., if a constant control law

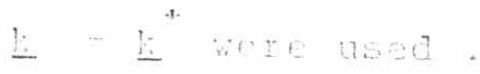

The totedere ingut aignal was chosen to be: $x(t)=0.3$

with an additive ontput disturbance: a 11$)=0.001 \sin 5.0 t$

The adaptaiof jaine were set ogual to four.i.e $\Gamma=4$,

but. the amplitude aria frequency of the sinusoidal disturbance were vatice for dicferent cases lo study their effects. The relatively largo value of adaptation gain jn (35) was chosen so that the

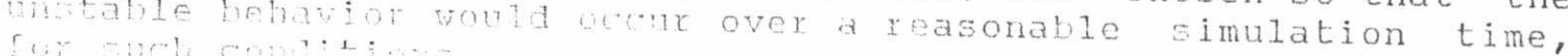


A11 simulatons wexe carried out with the discretized equivalent system. In order to obtain a discrete-time system which is equivalent to the system (29), the standard technique of discrate-time control system analysis was used (see [1], section 3.4). I sampling period of $\mathrm{T}_{\mathrm{S}}=0.04$ seconds was used. This represents fairly fast sampling, since it is approximately ten times as fast as the fastest dynamics in the plant [13].

It is seen from simmation results depicted in Figs. 3 and 4 that the stability of MRAC system using CAI, is more deteriorated when increasing the frequency of the sinusoidal disturbance and / or decreasing its amplitude. It is shown also that PRAM-modification does provide a stable closed-1oop control system with a reasonable performance, at conditions where none of the available standard adaptive control schemes can provide.

Fig. 5 inlicates that ERAM-modification, using the computed optimal value of $\mathrm{T}_{a}$ ( here, $\mathrm{T}_{\mathrm{a}}=1.8 \mathrm{sec}$ ) gives better response than any other one, in such conditions.

\section{CONCLUETONS}

In this paper, a modified MRAC algorithm with periodic Reset of Adaptation Mechanism (RRAM) has been developed. Such a controller can provide tability with better performance when the system operates in the presence of unmeasured and possibly persistant sinusofara? a sturbances.

The ir and scheme alleviates the dangerous problems of the unbounder parameter drift present in all available standard adative schemes, in such practical conditions. The analytical arguments and impovenents provided by the proposed algorithm has been verified by simulation results.

REFERENCES

1. Franklin, G.F. and powel1,J.D., "Digital Control of Dynamic Systems.", Addison-Wesley, Reading, (1980).

2. Toannou, E.A. and Tsakalis, K.S., "A Robust Direct Adaptive Controller,", IREE Trans. on Aut. Control, AC-31 (1986).

2. KandLahopoulos, T., Kohotovic, P.v. and Morse, A.s.,"Adaptive on1.put. Feedback Control of systems with output Nonlinearities". Tecinical repor', DC-126, Coordinate Science Laboratory, Univcrsity of r7frois at Urbana-Champaign (1990).

4. Kanel lakopoulos, I., Kokotovice,P.V. and Morse,A.S.,"Systematic Design of Adaptive Controllers For Feedback Linearizable sysLems.", TFEF Trans.on Aut. Control, No. 36, pp 1241-1235(1991).

5. Kreisselmcier, C. and Narendra, K.S., "Stable Model Reference Adaptive Control In The Prescence of Bounded Disturbances.", IEEE Trans. on Aut. Control, AC-27, pp 1169-1175 (1982).

6. Midaleton, R., Goodwin, G.C., Hill, D. and Mayne D.Q., "Design 
Issueg In Aogton Control.", IEEE Trans. on Aut. Control, $\mathrm{AC}-33, \mathrm{PD} 50-58(1988)$.

7. Naxendra, K.S. anc Anaswamy, A.M., " Robust Adaptive Control Tn The Frescen of Bounded Disturbances.", IEEE Trans. on Aut. Control, $A C 31, \mathrm{DP} 306-315$ (1986).

3. Narontr., K.A. Am Ansiswamy, A.M.," A New Adaptive Law For Robust Adaptation Without Eersistent Excitation.", IEEE Trans. on Aut. Control, AC-32, pp 134-145 (1987).

3. Orlicki, D., Thivani, I., Athans, M. and Stein, G., "Adaptive con! wo? With Variable Dead-Zone Nonlinearities.", Proc. of Wha Ampican Control Conf., pp 1893-1898 (1984).

10. Foteron, P.B. and Narendra,K.S., " Bounded Error Adaptive

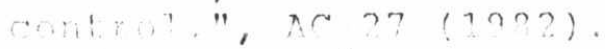

11. Pme 1, I. S. Anl Toammu, D.A.," Instability Mnalysis And RobuSt Adaptive Control of Robotic Manipulators.", IEeE J. of Romot nat Automation, No.15, (1989).

12. Robbins, 1 , and Horo. S.," A stochastic Approximation method., Ann. Math. Stat., 22, pp.400-407 (1951).

12. Rohrs, C," Adaptive Control in the Presence of Unmodeled Dyanics ", DH. D. Thesis, M.T.T., U.S.A. (1982).

14. Pho, C., Vahvani, T., Athans, M., and stein, G.," Robust-

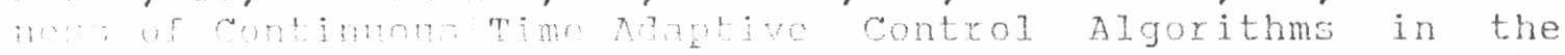

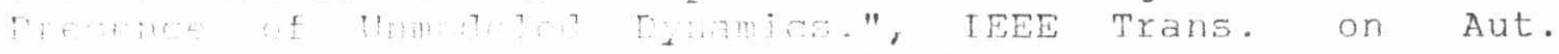

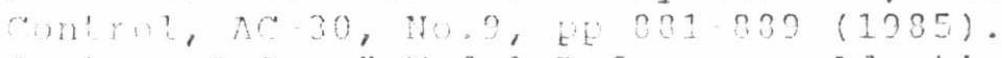

15. Sotry, S.S.," Moge Pformee Adaptive Control stability, Far. na pobastness.". IMA J. of Mathematical

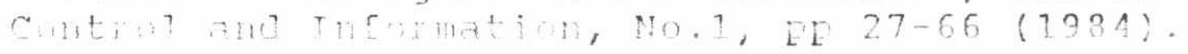

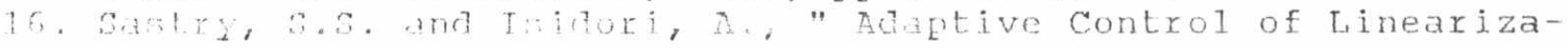
h? Cyetems.", IDEE Trans. On Aut. Control, No.34, pp $11231131(1383)$.

17. Tawit, A.Y. and Hahdan, A.M., " An Adaptive Model Reference Contanzer Wilh Bonned Gains.", Proc. of Third Asat conf., Hilil. Toul, Colloge, Cairu, Egypt, Vol. 3, pp 785-796 (1989).

1?. mol an, E. and Ljong, L., "Adaptive Control Based on Expli-

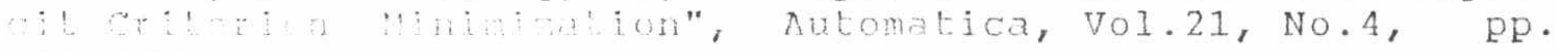

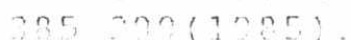

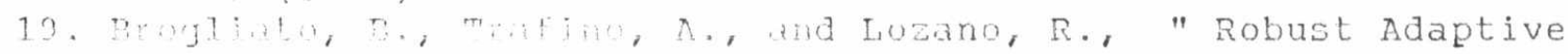
Coniru? of Clage of Nonlinear First Order Systems.",

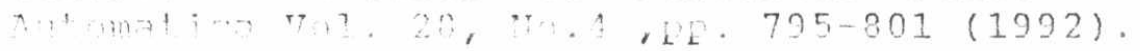



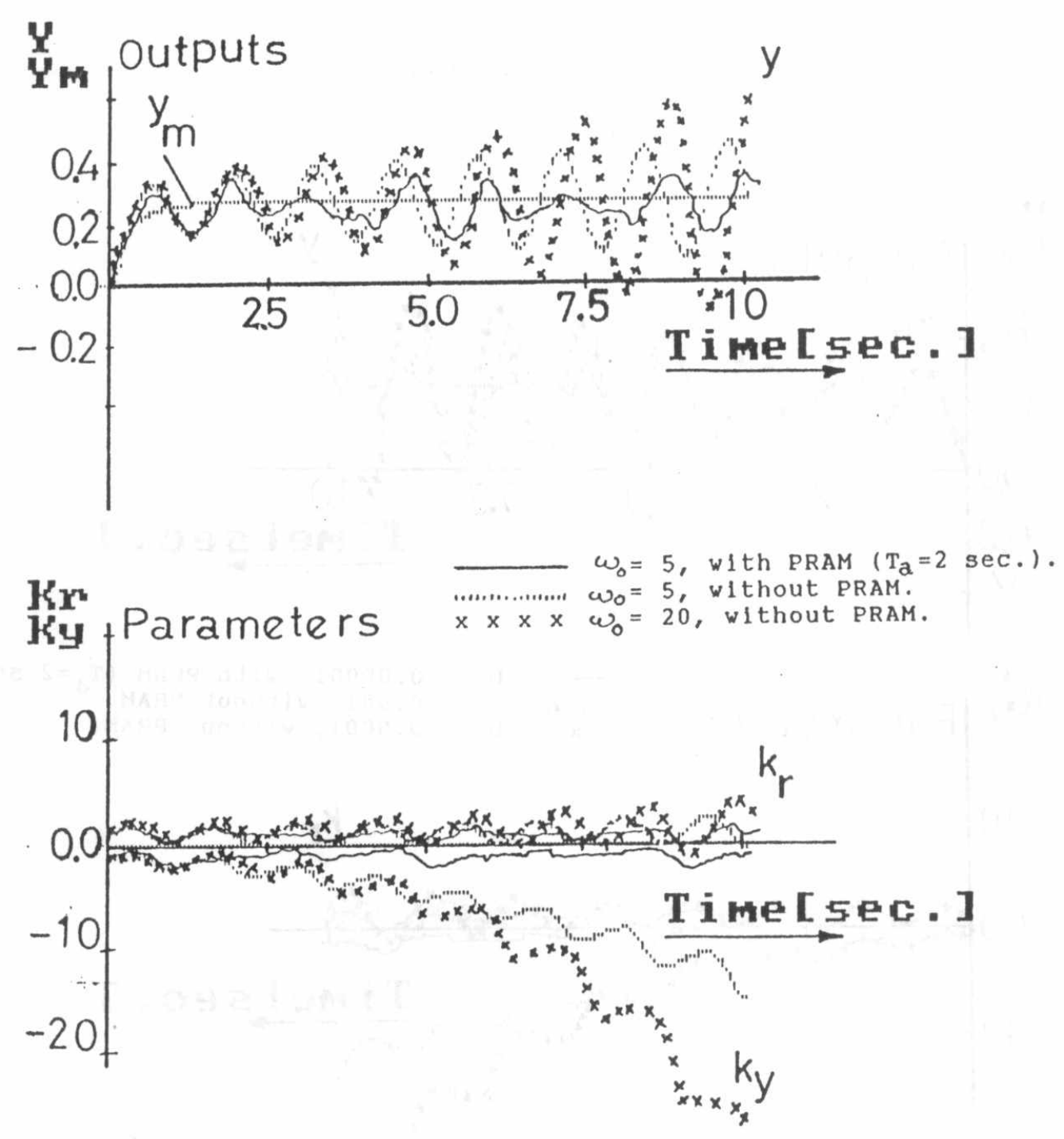

Fig.3. Simulation of CA1 with and without PRAM, $r(t)=0.3$ and $d(t)=0.001$ sin $\omega t$. 

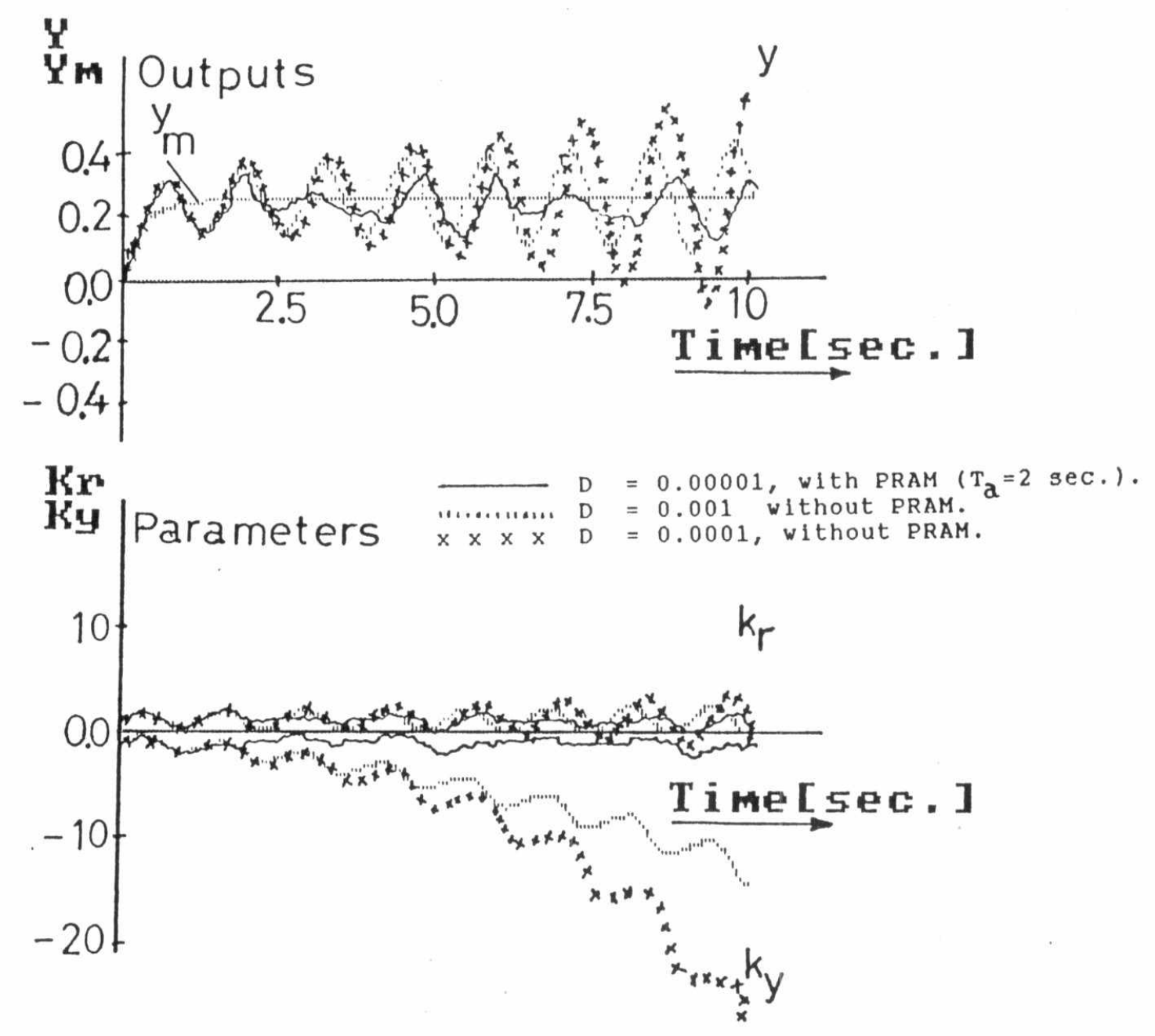

Fig.4. Simulation of CA1 with and without PRAM, $r(t)=0.3$ and $d(t)=D$ sin $5 t$. 


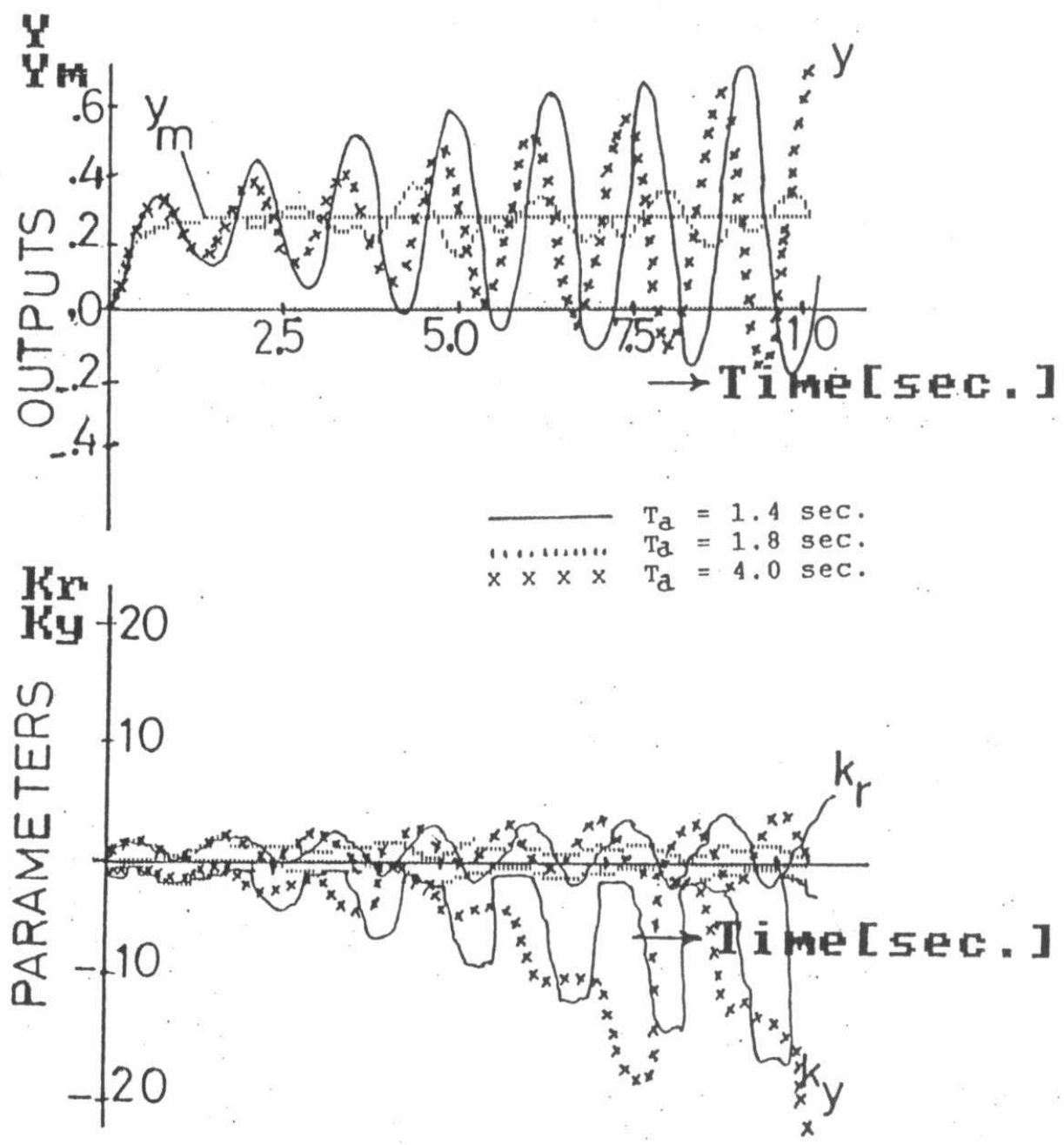

Fig.5. Simulation of CA1 with PRAM, $r(t)=0.3$, and $d(t)=1 \times 10^{-5} \sin 5 t$, at different $T_{a}$. 